\title{
The impact of smoking on outcomes following anterior cervical fusion-nonfusion hybrid surgery: a retrospective single-center cohort study
}

\author{
Han Wang ${ }^{1}$, Yang Meng ${ }^{1}$, Hao Liu ${ }^{1 *}$, Xiaofei Wang ${ }^{1}$ and Ying Hong ${ }^{2,3}$
}

\begin{abstract}
Background: There is mixed evidence for the impact of cigarette smoking on outcomes following anterior cervical surgery. It has been reported to have a negative impact on healing after multilevel anterior cervical discectomy and fusion, however, segmental mobility has been suggested to be superior in smokers who underwent one- or two-level cervical disc replacement. Hybrid surgery, including anterior cervical discectomy and fusion and cervical disc replacement, has emerged as an alternative procedure for multilevel cervical degenerative disc disease. This study aimed to examine the impact of smoking on intermediate-term outcomes following hybrid surgery.
\end{abstract}

Methods: Radiographical and clinical outcomes of 153 patients who had undergone continuous two- or three-level hybrid surgery were followed-up to a minimum of 2-years post-operatively. The early fusion effect, 1-year fusion rate, the incidence of bone loss and heterotopic ossification, as well as the clinical outcomes were compared across three smoking status groups: (1) current smokers; (2) former smokers; (3) nonsmokers.

Results: Clinical outcomes were comparable among the three groups. However, the current smoking group had a poorer early fusion effect and 1 -year fusion rate $(P<0.001$ and $P<0.035$ respectively). Both gender and smoking status were considered as key factors for 1-year fusion rate. Upon multivariable analysis, male gender $(\mathrm{OR}=6.664,95 \% \mathrm{Cl}$ : $1.248-35.581, P=0.026)$ and current smoking status $(\mathrm{OR}=0.009,95 \% \mathrm{Cl}: 0.020-0.411, P=0.002)$ were significantly associated with 1-year fusion rate. A subgroup analysis demonstrated statistically significant differences in both early fusion process $(P<0.001)$ and the 1 -year fusion rate $(P=0.006)$ across the three smoking status groups in female patients. Finally, non-smoking status appeared to be protective against bone loss (OR=0.427, 95\% Cl: 0.192-0.947, $P=0.036)$, with these patients likely to have at least one grade lower bone loss than current smokers.

Conclusions: Smoking is associated with poor outcomes following hybrid surgery for multilevel cervical disc disease. Current smokers had the poorest fusion rate and most bone loss, but no statistically significant differences were seen in clinical outcomes across the three groups.

Keywords: Cervical disc replacement, Anterior cervical discectomy and fusion, Hybrid surgery, Heterotopic ossification, Bone loss, Smoking

*Correspondence: dr.liuhao6304@yahoo.com

1 Department of Orthopaedic Surgery, West China Hospital, Sichuan University, No. 37 Guo Xue Road, Sichuan 610041 Chengdu, China

Full list of author information is available at the end of the article

\section{Background}

Anterior cervical discectomy and fusion (ACDF) is a traditional surgical procedure for the treatment of cervical degenerative disc disease (CDDD). Although original author(s) and the source, provide a link to the Creative Commons licence, and indicate if changes were made. The images or other third party material in this article are included in the article's Creative Commons licence, unless indicated otherwise in a credit line to the material. If material is not included in the article's Creative Commons licence and your intended use is not permitted by statutory regulation or exceeds the permitted use, you will need to obtain permission directly from the copyright holder. To view a copy of this licence, visit http://creativecommons.org/licenses/by/4.0/. The Creative Commons Public Domain Dedication waiver (http://creativeco mmons.org/publicdomain/zero/1.0/) applies to the data made available in this article, unless otherwise stated in a credit line to the data. 
satisfactory postoperative clinical outcomes have been reported from this procedure, non-fusion remains a concern. Previous literature suggests that the fusion rate may decrease with number of segments involved, the fusion rate for three-level ACDF has been reported as low as $56 \%$ up to 37 months after surgery [1]. In addition, multilevel fusion surgery decreases the cervical range of motion ( $\mathrm{ROM}$ ), leading to more pressure across adjacent levels. This may increase the risk of adjacent segmental degeneration (ASD). Cervical disc replacement (CDR) has therefore gained widespread popularity to preserve segmental mobility and mitigate against the risk of ASD. However, to date, Mobi-C and Prestige-LP artificial cervical discs are approved for use only in double-level CDDD by the Food and Drug Administration, although three-level CDR has been successfully performed, it is still considered an experimental treatment $[2,3]$. Hybrid surgery (HS), which combines ACDF and CDR has been proposed to mitigate these concerns. The objective of HS is to tailor the optimal surgical procedures to each target level according to its degenerative status. As a result, several series have demonstrated that this is a safe and effective surgical procedure for the treatment of multilevel CDDD [4-7].

Cigarette smoking is known to be associated with several health problems, including asthma, diabetes, cardiovascular disease, and other debilitating conditions. Nearly one billion people will die from smoking-related issues during the twenty-first century [8]. Smoking has also been demonstrated to worsen bone health, with an increased risk of osteoporotic fractures and delayed fracture healing in current smokers. A meta-analysis of 40,753 patients showed that smoking increases the risk of hip fracture by $30-40 \%$ [9]. A second meta-analysis of 59,232 patients reported a $25 \%$ increase in overall fractures and $84 \%$ increase in hip fractures in smokers compared with nonsmokers [10]. Moreover, several studies have reported a myriad of deleterious effects of smoking on patients undergoing spine surgery including increased complications, lower fusion rates, poorer clinical outcomes, and decreased quality of life [11-16]. Hilibrand et al. monitored 190 patients over two years and found smoking to be associated with a significant negative effect on healing and clinical recovery after multilevel cervical ACDF with autogenous interbody graft [17]. Contradictory to this, Tu et al. found that segmental mobility was marginally improved in smokers in patients with oneand two-level CDR than non-smokers [18]. However, the effect of smoking on anterior cervical HS is unclear. The adverse effects of smoking on arthrodesis and the potential benefits in arthroplasty contradict one another in the context of a hybrid approach.
In the present study, we aimed to explore the clinical impact of smoking status on fusion and bone loss in patients undergoing two- and three-level HS. To date, this is the first study to address this issue. We also hope to explore the impact of smoking on postoperative outcomes of HS to improve the evidence for implementation.

\section{Method \\ Patient population}

This retrospective study was conducted in according with the approval of our institutional review board. Consecutive patients who had undergone two- and three-level HS using the Prestige-LP artificial cervical disc (Medtronic, Minneapolis, Minnesota) and Zero-P device (Synthes GmbH Switzerland, Oberdorf, Switzerland) in our institution were included in this analysis. The inclusion criteria were as follow: (1) radiological findings consistent with foramen stenosis, ossification of posterior longitudinal ligament, obvious osteophytes on X-ray or CT scan or herniated nucleus pulposus on MRI; (2) symptomatic cervical myelopathy or radiculopathy or both; (3) failed conservative management for 6 weeks or more; (4) patient provided informed consent to undergo consecutive HS. The exclusion criteria were as follows: (1) less than 24 months of complete follow-up; (2) incomplete clinical and radiological data; (3) other indicators for cervical surgery such as spinal trauma, tumors, infection; (4) previous cervical spine surgery.

\section{Surgical technique}

The selection of either arthroplasty or arthrodesis during HS has strict indications. CDR was performed at levels without sagittal plane translation $>3 \mathrm{~mm}$ or sagittal plane angulation $>11^{\circ}$; without the $\mathrm{ROM}<3^{\circ}$; without a disc height loss $>50 \%$; and without facet joint degeneration, bridge osteophytes, or instability. ACDF was performed at the levels that did not meet the above criteria.

All operations were performed by the same senior spine surgeon. The patient was placed on the back with the neck in the neutral position. A standard right-side approach to the anterior cervical spine was adopted. After sufficient decompression of the entirety of the intervertebral space, CDR was performed before ACDF where indicated. A prothesis of the most suitable size was implanted into the intervertebral space, and the same artificial bone tissue was used in all the arthrodesis levels. Finally, C-arm fluoroscopy was used to confirm the appropriate position of the implants.

\section{Clinical and radiological evaluations}

Baseline demographics, clinical and radiological data were collected for all patients. Clinical outcomes were evaluated by the Japanese Orthopedic Association (JOA) 
scale, Neck disability Index (NDI), and visual analog scale (VAS) for neck and arm pain both preoperatively and at the final follow-up appointment. Pre- and postoperative radiological evaluations included X-ray, $\mathrm{CT}$, and MRI. Lateral and extension-flexion radiographs, sagittal reconstructed CT, and T2-weighted MRI were obtained at specified time points. Segmental ROM at the target level and the ROM of C2-7 was defined as the difference in the Cobb angle between extension and flexion radiographs. For patients with two-level CDR, the mean value of segmental ROM was used for further analysis. Bone mineral density (BMD) was measured at the L2-4 vertebral body. Heterotopic ossification (HO) was using the McAfee classification [19] (Table 1). The classification of bone loss (BL) followed a validated methodology detailed in full elsewhere, based on a classification system reported by Saleh et al. in 2004 [20, 21] (Table 2). For patients with two-level CDR, the more severe degree of $\mathrm{HO}$ and $\mathrm{BL}$ was recorded. McAfee grade III and IV HO were classified as high-grade HO. Early fusion process was assessed using sagittal reconstructed CT scans at three-month follow-up, measuring the height of new bone tissue at the posterior aspect of the cage (Fig. 1.) For patients with two-level ACDF, the mean value of new bone tissue was used for further analysis. The criteria to confirm fusion at 1-year were segmental ROM less than $3^{\circ}$ in X-ray and continuous bone bridge demonstrated in CT imaging. For patients with two-level ACDF, if both levels had achieved fusion they were classified as "fusion", otherwise they were classified as "non-fusion". All measurements and ratings were completed by two independent spine surgeons, with corroboration by a third senior spine surgeon in case of disagreement.

\section{Study group and statistical analysis}

The main explanatory variable for this study was smoking status. All patients were classified into one of three groups according to their smoking status at the time of surgery: (1) patients that had smoked cigarettes within

Table 1 Classification of HO following CDR

\begin{tabular}{|c|c|}
\hline Grade & Definition \\
\hline 0 & No HO was observed \\
\hline 1 & $\mathrm{HO}$ does not occur within the disc space \\
\hline 2 & $\begin{array}{l}\mathrm{HO} \text { is present between the planes } \\
\text { formed by the vertebral endplates but } \\
\text { does not block spinal motion }\end{array}$ \\
\hline 3 & $\begin{array}{l}\text { The range of motion of the vertebral } \\
\text { endplates is blocked by the formation } \\
\text { of } \mathrm{HO} \text { or osteophytes }\end{array}$ \\
\hline 4 & HO causes bony fusion \\
\hline
\end{tabular}

HO heterotopic ossification, CDR cervical disc replacement
Table 2 Classification for BL after CDR

\begin{tabular}{ll}
\hline Grade & Definition \\
\hline 0 & None. BL accounts for $0-1 \%$ of the length of endplate \\
1 & Mild. BL accounts for $1-5 \%$ of the length of endplate \\
2 & Moderate. BL accounts for $5-10 \%$ of the length of endplate \\
3 & Severe without collapse. BL accounts for $>10 \%$ of the \\
4 & length of endplate without prosthesis subsidence \\
& $\begin{array}{l}\text { Severe with collapse. BL accounts for }>10 \% \text { of the length } \\
\text { of endplate with prosthesis subsidence }\end{array}$
\end{tabular}

$B L$ bone loss, $C D R$ cervical disc replacement

the year prior to surgery were defined as the current smokers; (2) patients with a smoking history but with cessation of smoking for more than 1 year before surgery were defined as former smokers; (3) patients who had never smoked were defined as non-smokers. All patients were recommended to stop smoking postoperatively. Continuous variables were summarized using the mean average and standard deviation. Frequency data is presented as quantities and proportion. Statistical analysis was performed using SPSS 19.0 for windows (IBM SPSS Inc, New York, USA). ANOVA analysis was used to compare continuous data across the three explanatory groups and Fisher's least significant difference (LSD) test was used for pairwise comparisons. Inter- and intra-observer reliability were assessed using intra-class correlation coefficient (ICC). Kruskal-Wallis $\mathrm{H}$ test was used to explore factors associated with bony fusion, and multiple ordered regression was used to identify the risk factors

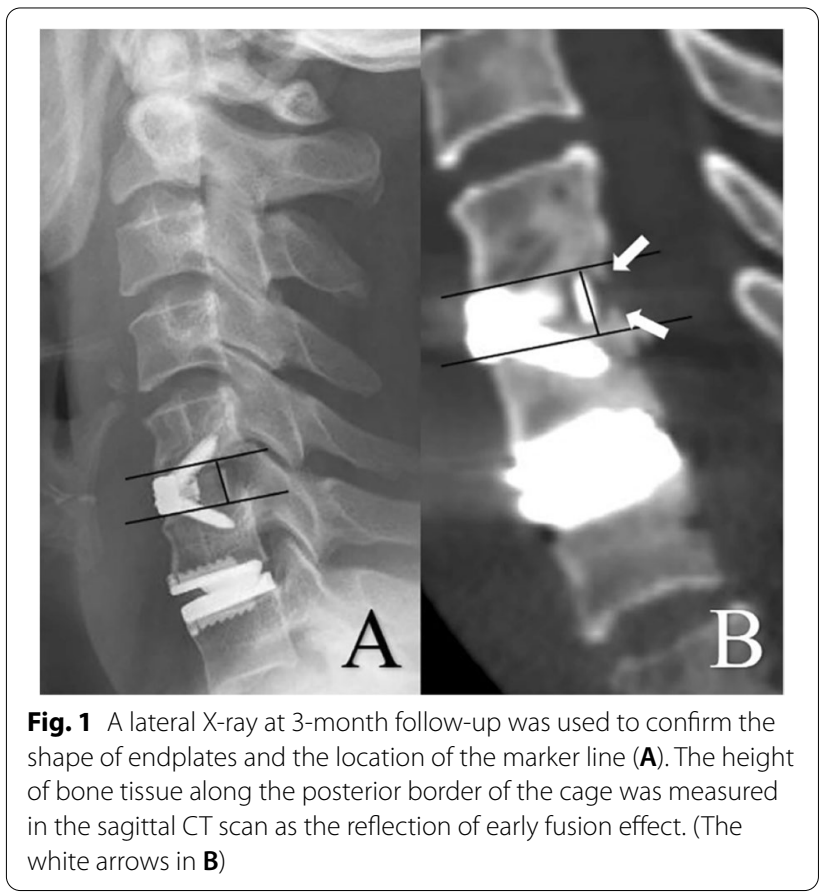


associated with BL. Both were presented as adjusted odds ratio (OR) with $95 \%$ confidence intervals $(95 \% \mathrm{CI})$. The alpha level of significance was set at 0.05 .

\section{Results}

\section{Baseline demographics}

A total of 153 patients with complete clinical and radiological data were included in analyses. Of these, 51 (33.33\%) were male and $102(66.67 \%)$ were female. The mean age was 50.11 years old, with a mean follow-up of 40.82 months. In total, 79 patients underwent 2-level HS and 74 underwent 3-level HS. Other demographics data are summarized in Table 3.

\section{Inter- and intra-observer differences}

The inter- and intra-observer reliability were 0.94 and 0.91 for preoperative segmental ROM, 0.87 and 0.92 for preoperative C2-7 ROM, 0.92 and 0.96 for postoperative segmental ROM, 0.92 and 0.89 for postoperative C2-7 ROM, 0.98 and 0.97 for $\mathrm{HO}, 0.91$ and 0.96 for bone loss, 0.95 and 0.91 for early fusion effect, 0.97 and 0.95 for 1 -year fusion rate.

\section{Smoking status}

There were 40 (26.14\%) current smokers, 34 (22.22\%) former smokers and 79 (51.63\%) non-smokers included in this study. Men were most likely to be current smokers while women were most likely to be nonsmokers $(47.06 \%$ vs $66.67 \%, P<0.001)$. The BMD value in the nonsmoking group was numerically higher than those of other two groups, but this was not statistically significant. The clinical and radiological outcomes by the point of final followup were comparable across all three groups. No statistical differences were found in the incidence of $\mathrm{HO}$ and $\mathrm{BL}$,

Table 3 Baseline demographic and clinical characteristic

\begin{tabular}{ll}
\hline Variable & Value (\%) \\
\hline Number of patients & 153 \\
Age (years) & $50.11 \pm 7.48$ \\
Sex & \\
Male & 51 \\
Female & 102 \\
Involved levels & \\
Two & 79 \\
Three & 74 \\
T value (spine) & $0.30 \pm 1.03$ \\
Follow-up (months) & $40.82 \pm 15.63$ \\
HO formation & $92(58.97 \%)$ \\
High-grade HO formation & $16(10.26 \%)$ \\
Bone loss & $84(53.85 \%)$ \\
\hline
\end{tabular}

HO heterotopic ossification but the current smoking group had the worst early fusion effect $(P<0.001)$ and lowest 1 -year fusion rate $(P<0.035)$ (Table 4) Upon multivariable analysis, both gender and smoking status were associated with 1-year fusion rate (Fig. 2). Male patients (OR=6.664, 95\% CI: 1.248 $35.581, P=0.026)$ displayed increased odds whilst nonsmokers demonstrated reduced odds $(\mathrm{OR}=0.009,95 \%$ CI: $0.020-0.411, P=0.002$ ) (Table 5). Subgroup analysis was therefore used to further explore the effect of gender and smoking status on the postoperative outcomes. Although there were significant differences in early fusion process among the three smoking status groups for male group $(P<0.001)$, no significant differences were observed in 1-year fusion rate (Table 6). However, for female patients, statistical differences were found in both early fusion process $(P<0.001)$ and the 1 -year fusion rate $(P=0.006)$ (Table 7$)$. Additionally, no significant differences were observed in the degree of $\mathrm{HO}$ among the three smoking status groups, however, the degree of $\mathrm{BL}$ in current smokers was found to be the most severe $(P<0.001)$ (Table 8). Reinforcing this, multiple ordered regression demonstrated that sex was not associated with BL, whilst smoking status was significantly associated (Table 9). Current smokers demonstrated the most serious BL, and patients who had never smoked were likely to have at least one grade lower BL than current smokers $(\mathrm{OR}=0.427,95 \%$ CI: 0.192-0.947, $P=0.036)$.

\section{Discussion}

HS, including both CDR and ACDF, is now one of the most common surgical procedures for the treatment of patients with cervical spondylosis. Previous studies have suggested that smoking may limit bony fusion following ACDF, but has a potential advantage in the ROM permitted after CDR. For the patients undergoing a hybrid approach, evidence is conflicting, with an unclear effect of smoking where both arthroplasty and arthrodesis are performed. To the best of our knowledge, this is the first study that focuses on this issue, it aimed to explore the impact of smoking on clinical outcomes and complications after HS.

The negative impact of smoking on bone health has been well described, including increased rates of osteoporosis, osteoporotic fracture and bone loss. The Nurses' Health Study, a prospective cohort of 121,701 female nurses aged between $30-55$ years old, found that current smokers had a dose-independent increase in the incidence of hip fracture compared with non-smokers [22]. A Norwegian cohort study of 34,856 adults aged more than 50 years old showed smoking was associated with the incidence of the hip fracture in both sexes, and that effect was independent off body mass index and physical inactivity [23]. Additionally, a community-based, 
Table 4 Comparison of clinical and radiological data among current smokers, former smokers and non-smokers

\begin{tabular}{|c|c|c|c|c|}
\hline & Current smoker & Former smoker & Nonsmoker & $P$ value \\
\hline Number of patients & 40 & 34 & 79 & \\
\hline Sex (M:F) & & & & $<0.001^{*}$ \\
\hline Male & 24 & 16 & 11 & \\
\hline Female & 16 & 18 & 68 & \\
\hline Age (years) & $50.00 \pm 6.08$ & $51.62 \pm 7.40$ & $49.52 \pm 8.13$ & 0.393 \\
\hline Follow-up (months) & $52.10 \pm 13.95$ & $47.71 \pm 14.82$ & $47.65 \pm 16.69$ & 0.306 \\
\hline T value (spine) & $0.24 \pm 1.01$ & $0.26 \pm 1.19$ & $0.34 \pm 0.97$ & 0.861 \\
\hline \multicolumn{5}{|l|}{ Preoperative outcomes } \\
\hline $\mathrm{JOA}$ & $10.60 \pm 1.03$ & $11.12 \pm 1.59$ & $10.80 \pm 1.39$ & 0.261 \\
\hline $\mathrm{NDI}$ & $30.50 \pm 3.63$ & $30.47 \pm 3.86$ & $31.37 \pm 3.87$ & 0.362 \\
\hline VAS-arm & $5.93 \pm 1.00$ & $5.44 \pm 1.37$ & $5.68 \pm 1.20$ & 0.224 \\
\hline VAS-neck & $5.98 \pm 0.83$ & $5.68 \pm 1.12$ & $5.90 \pm 1.08$ & 0.435 \\
\hline Segmental ROM & $9.48 \pm 5.11$ & $11.25 \pm 4.76$ & $10.13 \pm 4.51$ & 0.273 \\
\hline C2-7 ROM & $49.16 \pm 13.81$ & $53.44 \pm 12.66$ & $48.99 \pm 12.16$ & 0.210 \\
\hline Involved levels & & & & 0.116 \\
\hline $\mathrm{C} 3 / 4$ & 14 & 10 & 7 & \\
\hline$C 4 / 5$ & 38 & 28 & 59 & \\
\hline $\mathrm{C} 5 / 6$ & 40 & 30 & 76 & \\
\hline $\mathrm{C} 6 / 7$ & 22 & 14 & 42 & \\
\hline \multicolumn{5}{|l|}{ Final outcomes } \\
\hline $\mathrm{JOA}$ & $15.55 \pm 0.81$ & $15.79 \pm 1.23$ & $15.76 \pm 1.05$ & 0.511 \\
\hline $\mathrm{NDI}$ & $8.48 \pm 2.61$ & $7.85 \pm 3.09$ & $7.86 \pm 2.59$ & 0.467 \\
\hline VAS-arm & $1.63 \pm 0.67$ & $1.44 \pm 1.05$ & $1.63 \pm 0.89$ & 0.544 \\
\hline VAS-neck & $1.50 \pm 0.51$ & $1.59 \pm 0.50$ & $1.48 \pm 0.60$ & 0.636 \\
\hline Segmental ROM & $7.33 \pm 3.53$ & $7.58 \pm 4.09$ & $8.17 \pm 4.04$ & 0.508 \\
\hline C2-7 ROM & $36.26 \pm 10.65$ & $36.70 \pm 11.38$ & $37.47 \pm 10.89$ & 0.838 \\
\hline Heterotopic ossification & 24 & 22 & 46 & 0.812 \\
\hline Bone loss & 22 & 22 & 40 & 0.386 \\
\hline Early fusion effect & $2.35 \pm 0.73$ & $3.20 \pm 1.59$ & $3.62 \pm 1.41$ & $<0.001^{*}$ \\
\hline 1-year fusion rate & 33 & 32 & 76 & $0.035^{*}$ \\
\hline
\end{tabular}

${ }^{*} P<0.05$, statistically significant

longitudinal, epidemiologic study of osteoporosis in 1789 people over the age of 60 showed smoking was associated with 5-8\% lower BMD at the spine and the femoral neck [24]. The present study corroborated these findings, demonstrating that BMD was higher in the non-smokers than in current and former smokers. Our data suggest a degree of recovery of bone health in former smokers, with a mean BMD value between that of current and non-smokers. However, previous studies have reported that few differences in BMD was observed between current and former smokers [24, 25]. This warrants further investigation in future work.

In cervical spine arthrodesis, several studies have shown that smoking has a negative impact on healing following spinal fusion surgery [11, 15, 17]. This is supported by a considerable body of translational research devoted to exploring the mechanistic effects of smoking on bone healing. Chang et al. reported that cigarette smoking impairs angiogenesis in early bone healing process and delays fracture union [26]. Ueng et al. hypothesized that smoking delays mineralization during the bone healing process and further decreases the mechanical strength of the regenerating bone [27]. EI-Zawawy et al. found that smoking delays chondrogenesis during bone healing in a mouse model [28]. Supporting this, in our study less new bone tissue was measured at the posterior margin of the cage in the current smokers, compared with the former and non-smokers. In further laboratory work, Davies et al. reported nicotine to have deleterious effects on wound healing through increased vasoconstriction [29]. Gaston et al. put forward several hypotheses about the impact of smoking on bone healing process, including reduced blood supply, deficiency of vitamins and 


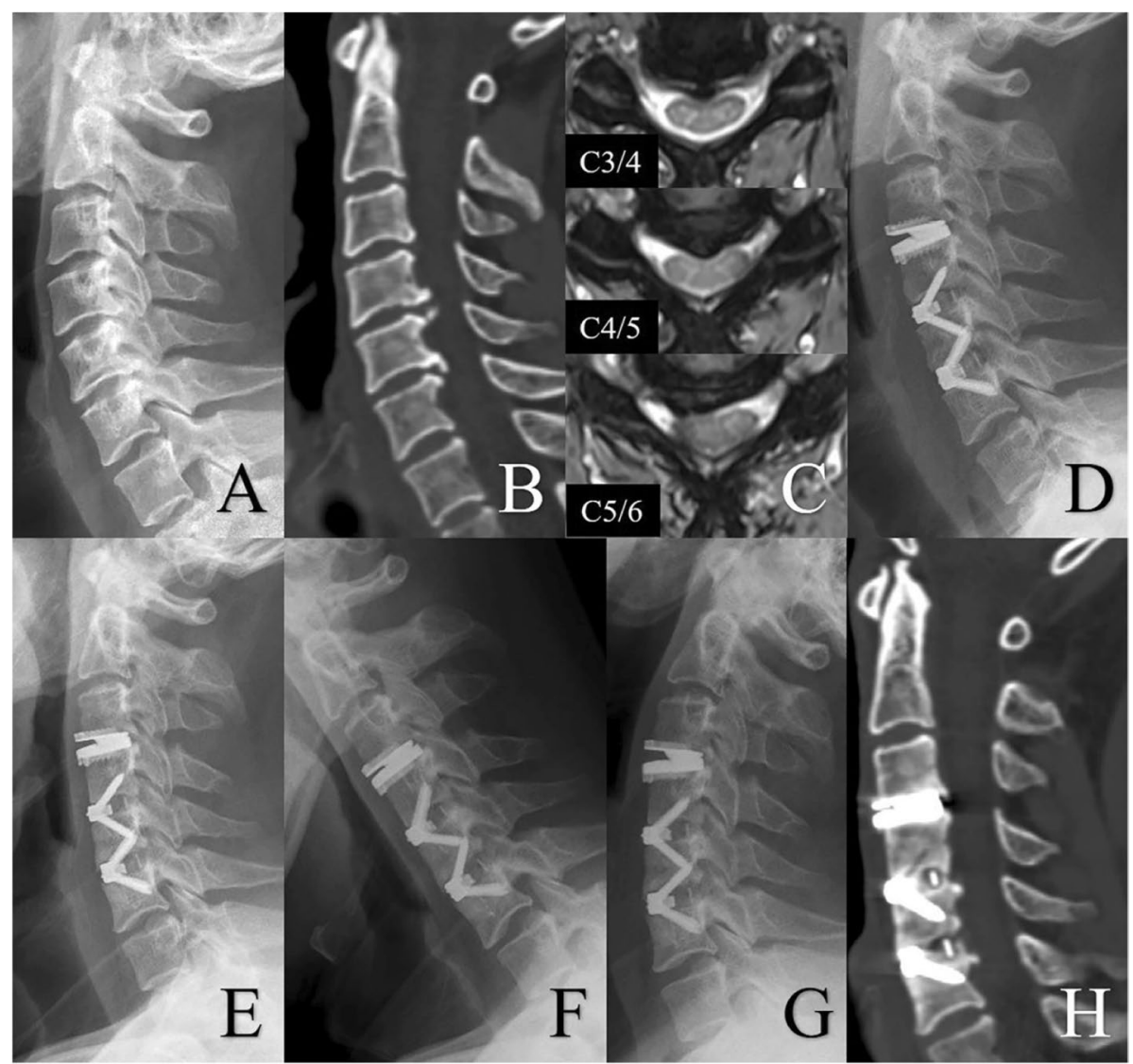

Fig. 2 Radiologic examinations of a 45-year older woman with neck pain for 1 year, who had cigarette consumption for more than 10 years. Preoperative lateral X-ray showed good cervical lordosis (A). However, a sagittal CT scan showed osteophytes at the posterior border of C4/5 and C5/6 (B). MRI demonstrated spinal cord compression at C3/4, C4/5 and C5/6 (C). The patient underwent HS, including CDR at C3/4, and ACDF at C4/5 and C5/6 (D). At 1-year follow-up, lateral X-ray shows satisfactory cervical lordosis (E), and extension-flexion view showed good cervical ROM (F and $\mathbf{G}$ ). However, a postoperative CT scan showed incomplete bony fusion at both two arthrodesis levels (H)

Table 5 Factors associated with one-year fusion status in the binary logistic regression model

\begin{tabular}{lcl}
\hline & P value & OR value \\
\hline Male & $0.026^{*}$ & $6.664(1.248-35.581)$ \\
Female & - & \\
Current smoker & $0.002^{*}$ & $0.090(0.020-0.411)$ \\
Former smoker & 0.360 & \\
Nonsmoker & - & \\
\hline
\end{tabular}

${ }^{*} P<0.05$, statistically significant

antioxidants, and high levels of reactive oxygen intermediates [30].

Gender is a potential confounding factor in this study, with a higher rate of current smokers than non-smokers in male patients, and a significantly higher fusion rate in male compared with female patients. To explore the effect of smoking on the bony fusion, subgroup analyses were performed by gender. No significant differences were observed in male patients across smoking status groups. For female patients in the current smoking group, a lower fusion rate was observed than that of former smokers and nonsmokers. One reason for this may be related to estrogen levels. The average age of included patients was around 50 years old, which commonly represents the perimenopausal period. A decrease in the circulating estrogen level may lead to a decrease in BMD and bony fusion. Additionally, it has been previously reported that smoking may lead to decreased bio-availability of estrogen in target tissues [31]. This may explain the reason why women in the current smoking group showed a poorer 1-year fusion rate. Although the reasons are likely to be multifactorial, our study broadly confirms that smoking has a negative impact on bone healing, and may impair early osteogenesis and fusion of arthrodesis levels in patients undergoing HS. 
Table 6 The impact of smoking on male anterior cervical HS patients

\begin{tabular}{lllll}
\hline & Current smoker & Former smoker & Nonsmoker & P value \\
\hline Number of patients & 24 & 16 & 11 & \\
Final Outcomes & & & $16.00 \pm 1.18$ & 0.335 \\
JOA & $15.50 \pm 0.83$ & $15.94 \pm 1.39$ & $6.55 \pm 0.93$ & 0.192 \\
NDI & $8.04 \pm 1.57$ & $7.81 \pm 3.47$ & $1.55 \pm 0.52$ & 0.611 \\
VAS-arm & $1.58 \pm 0.65$ & $1.31 \pm 1.25$ & $1.55 \pm 0.52$ & 0.750 \\
VAS-neck & $1.50 \pm 0.51$ & $1.63 \pm 0.50$ & $7.83 \pm 3.14$ & 0.520 \\
Segmental ROM & $6.42 \pm 2.81$ & $6.98 \pm 4.20$ & $34.56 \pm 10.46$ & 0.870 \\
C2-7 ROM & $36.29 \pm 9.92$ & $35.09 \pm 9.36$ & $5.35 \pm 2.18$ & 11 \\
Early fusion effect & $2.63 \pm 0.57$ & $4.10 \pm 1.66$ & $0.001^{*}$ \\
1-year fusion rate & 22 & 16 & 0.699 \\
\hline
\end{tabular}

HS hybrid surgery, JOA Japanese Orthopaedic Association, NDI neck disability index, VAS visual analog scale, $R O M$ range of motion. ${ }^{*} P<0.05$, statistically significant

Table 7 The impact of smoking on female anterior cervical HS patients

\begin{tabular}{lllll}
\hline & Current smoker & Former smoker & Nonsmoker & P value \\
\hline Number of patients & 16 & 18 & 68 & \\
Final Outcomes & & & $15.72 \pm 1.03$ & 0.935 \\
JOA & $15.63 \pm 0.81$ & $15.67 \pm 1.08$ & $8.07 \pm 2.71$ & 0.374 \\
NDI & $9.13 \pm 3.63$ & $7.89 \pm 2.81$ & $1.65 \pm 0.94$ & 0.901 \\
VAS-arm & $1.69 \pm 0.70$ & $1.56 \pm 0.86$ & $1.47 \pm 0.61$ & 0.857 \\
VAS-neck & $1.50 \pm 0.52$ & $1.56 \pm 0.51$ & $8.22 \pm 4.18$ & 0.902 \\
Segmental ROM & $8.70 \pm 4.12$ & $8.12 \pm 4.04$ & $37.95 \pm 10.96$ & 0.853 \\
C2-7 ROM & $36.23 \pm 12.00$ & $38.14 \pm 13.02$ & $3.34 \pm 1.02$ & $<0.001^{*}$ \\
Early fusion effect & $1.92 \pm 0.75$ & $2.34 \pm 1.02$ & 65 & $0.006^{*}$ \\
1-year fusion rate & 11 & 16 & & \\
\hline
\end{tabular}

HS hybrid surgery, JOA Japanese Orthopaedic Association, NDI neck disability index, VAS visual analog scale, ROM range of motion. ${ }^{*} P<0.05$, statistically significant

Table 8 Comparison of degree of $\mathrm{HO}$ and $\mathrm{BL}$ among the current smokers, former smokers and non-smokers

\begin{tabular}{lllll}
\hline & $\begin{array}{l}\text { Current } \\
\text { smoker }\end{array}$ & $\begin{array}{l}\text { Former } \\
\text { smoker }\end{array}$ & Nonsmoker & P value \\
\hline $\begin{array}{l}\text { Heterotopic } \\
\text { Ossification }\end{array}$ & 24 & 22 & 46 & 0.097 \\
1 & 0 & 4 & 6 & \\
2 & 18 & 14 & 34 & \\
3 & 0 & 4 & 2 & \\
4 & 6 & 0 & 4 & \\
Bone loss & 22 & 22 & 40 & \\
1 & 10 & 12 & 39 & \\
2 & 6 & 9 & 0 & \\
3 & 6 & 1 & 1 & \\
4 & 0 & 0 & 0 & \\
\hline
\end{tabular}

$H O$ heterotopic ossification, $B L$ bone loss. ${ }^{*} P<0.05$, statistically significant

In terms of the effect of smoking on the arthroplasty levels, however, current research is very limited. To date, only a single retrospective study of 197 patients who
Table 9 Factors associated with bone loss in the multiple ordered logistic regression model

\begin{tabular}{lcl}
\hline & $P$ value & OR value \\
\hline Nonsmoker & $0.036^{*}$ & $0.427(0.192-0.947)$ \\
Former smoker & 0.737 & \\
Current smoker & - & \\
Female & 0.593 & \\
Male & - & \\
${ }^{*} P<0.05$, statistically significant & &
\end{tabular}

underwent one- or two-level CDR has been reported. At an average of 3.5 years follow-up, Tu et al. reported similar clinical outcomes between current smokers and non-smokers, but with a slightly better segmental ROM observed in smokers [18]. In the present study, no significant differences were found in clinical outcomes or ROM across the three smoking status groups. However, the patients in the current smoking group had the highest level of BL among the three groups. Wang et al. performed a systematic review of six studies including 440 
patients who underwent CDR across 536 segments. They found that patients with BL achieved similar clinical outcomes compared with those without BL [32]. Wu et al. performed a retrospective study of 396 patients in a single center and found BL did not affect clinical outcomes but patients with BL had a larger segmental ROM [33]. However, Hacker et al. reported that one patient with BL had recurrent neck and arm pain for 52 months postoperatively, with radiological evaluations demonstrating segmental kyphosis. This patient eventually required revision surgery and two-level ACDF [34]. Again, a wealth of basic research has demonstrated the impact of smoking on resorption and BL in animal models [35, 36]. Although the clinical outcomes associated with BL remain unclear, it should be recognized that severe $\mathrm{BL}$ can lead to prosthesis collapse, and a need for revision. Additionally, no significant differences were observed in the incidence of $\mathrm{HO}$ among the three smoking groups, but with a trend towards more severe $\mathrm{HO}$ in current smokers. Although $\mathrm{HO}$ is essentially an osteogenic process, its true mechanism is still unclear. Male gender, old age and multilevel diseases have been previously considered to be risk factors for $\mathrm{HO}[37,38]$. A meta-analysis of 94 studies indicated that the incidence of $\mathrm{HO}$ increased over time in studies with longer follow-up [39]. Another meta-analysis compared the incidence of high-grade $\mathrm{HO}$ across studies and found a significant variability between different prostheses [40]. Additionally, endplate coverage, segmental angle and center of rotation were all considered to be associated with the presence of $\mathrm{HO}$ [41-43]. However, the effect of smoking on $\mathrm{HO}$ requires further exploration.

In summary, smoking had a negative impact on patients undergoing HS. The patients in the current smoking group had a worse early fusion process and 1 -year fusion rate, particularly in female patients, as well as more serious BL. Smoking cessation is recommended for all patients before HS. Additionally, all patients undergoing $\mathrm{HS}$ are required to wear a collar for at least three months in our institution, with supervised activity permitted during the first three weeks postoperatively. Considering the poor early fusion effect and stability in current smokers, protracted periods in a neck brace and reduced activity may be necessary for these patients in the early postoperative period. The present study has some limitations. First, the retrospective design may have led to potential selection bias. The dose and duration of smoking were also unavailable. Second, passive smoking history was not included as a factor in the multivariable models, which may have introduced unmeasured confounding. Third, the patient sample was small and the follow-up duration was short, with data only from a single institution. A multicenter study with a larger sample size and longer follow-up period would be important to provide stronger evidence.

\section{Conclusion}

This study showed that smoking has a negative impact on the patients undergoing HS. Smoking cessation is important to consider for these patients before surgery in order to reduce risk and approach baseline. The patients in the current smoking group had a worse early fusion effect and 1-year fusion rate, as well as more serious BL. However, no significant differences were observed in clinical outcomes among the three groups.

\section{Abbreviations}

ACDF: Anterior cervical discectomy and fusion; CDDD: Cervical degenerative disc disease; ROM: Range of motion; ASD: Adjacent segmental degeneration; CDR: Cervical disc replacement; HS: Hybrid surgery; JOA: Japanese Orthopaedic Association; NDI: Neck disability index; VAS: Visual analog scale; $\mathrm{HO}$ Heterotopic ossification; BMD: Bone mineral density; BL: Bone loss; ICC: Intraclass correlation coefficient.

\section{Acknowledgements}

Not applicable.

\section{Authors' contributions}

H.W. and Y.M. analyzed and interpreted all data, performed statistical analysis and prepared the manuscript. Collection and analysis of radiographs were performed by Y.H. and X.W.. H.L. designed and supervised the study. All authors have read and approved the final manuscript.

\section{Funding}

This study was supported by the 1.3.5 Project for Disciplines of Excellence (ZYJC18029), the Post-Doctor Research Project (2018HXBH002), and the West China Nursing Discipline Development Special Fund Project (HXHL19016) of West China Hospital, Sichuan University.

Availability of data and materials

All data generated or analyzed during this study are included in this article.

\section{Declarations}

Ethics approval and consent to participate

The study was approved by the institutional ethics committee of West China Hospital of Sichuan University, and follows the ethics principles of the Declaration of Helsinki 1964, and the informed consent was waived due to the retrospective nature of this study. The authors declare that all methods were carried out in accordance with relevant guidelines and regulations.

\section{Consent for publication}

Not applicable.

\section{Competing interests}

The authors declare that they have no competing interests.

\section{Author details}

${ }^{1}$ Department of Orthopaedic Surgery, West China Hospital, Sichuan University, No. 37 Guo Xue Road, Sichuan 610041 Chengdu, China. ${ }^{2}$ Department of Anesthesia and Operation Center, West China Hospital, Sichuan University, Sichuan, China. ${ }^{3}$ West China School of Nursing, West China Hospital, Sichuan University, Sichuan, China. 
Received: 25 January 2021 Accepted: 17 June 2021

Published online: 09 July 2021

\section{References}

1. Emery SE, Fisher JR, Bohlman HH: Three-level anterior cervical discectomy and fusion: radiographic and clinical results. Spine (Phila Pa 1976) 1997, 22(22):2622-2624; discussion 2625.

2. Friesem T, Khan S, Rajesh M, Berg A, Reddy G, Bhatia C: Long Term Follow Up of Multi-Level (Three \& Four Levels) Cervical Disc Arthroplasty—Results From a Single Centre \%J. Spine J. 2017, 17(3).

3. Chang HK, Huang WC, Tu TH, Fay LY, Kuo CH, Chang CC, Wu CL, Lirng JF, Wu JC, Cheng H, et al. Radiological and clinical outcomes of 3-level cervical disc arthroplasty. J Neurosurg Spine. 2019;32(2):174-81.

4. Wang H, Huang K, Liu H, Meng Y, Wang X, Ding C, Hong Y. Is Cervical Disc Replacement Valuable in 3-Level Hybrid Surgery Compared with 3-Level Anterior Cervical Discectomy and Fusion? World Neurosurg. 2021;146:e151-e160.

5. Wang H, Meng Y, Liu H, Wang X, Ding C: A Comparison of 2 Anterior Hybrid Techniques for 3-Level Cervical Degenerative Disc Disease. Med Sci Monit 2020, 26:e927972.

6. Zhang J, Meng F, Ding Y, Li J, Han J, Zhang X, Dong W: Comprehensive Analysis of Hybrid Surgery and Anterior Cervical Discectomy and Fusion in Cervical Diseases: A Meta-Analysis. Medicine (Baltimore) 2020, 99(5):e19055.

7. Hollyer MA, Gill EC, Ayis S, Demetriades AK. The safety and efficacy of hybrid surgery for multilevel cervical degenerative disc disease versus anterior cervical discectomy and fusion or cervical disc arthroplasty: a systematic review and meta-analysis. Acta Neurochirurgica. 2020;162(2):289-303.

8. Wipfli H, Samet JM. Global economic and health benefits of tobacco control: part 1. Clin Pharmacol Therapeutics. 2009;86(3):263-71.

9. Ward KD, Klesges RC. A meta-analysis of the effects of cigarette smoking on bone mineral density. Calcified Tissue Int. 2001;68(5):259-70.

10. Kanis JA, Johnell O, Oden A, Johansson H, De Laet C, Eisman JA, Fujiwara S, Kroger H, McCloskey EV, Mellstrom D, et al. Smoking and fracture risk: a meta-analysis. Osteoporosis Int. 2005;16(2):155-62.

11. Andersen T, Christensen FB, Laursen M, Høy K, Hansen ES, Bünger C: Smoking as a predictor of negative outcome in lumbar spinal fusion. Spine (Phila Pa 1976) 2001, 26(23):2623-2628.

12. Bisson EF, Bowers CA, Hohmann SF, Schmidt MH. Smoking is Associated with Poorer Quality-Based Outcomes in Patients Hospitalized with Spinal Disease. Front Surg. 2015:2:20

13. De la Garza Ramos R, Goodwin CR, Qadi M, Abu-Bonsrah N, Passias PG, Lafage V, Schwab F, Sciubba DM: Impact of Smoking on 30-day Morbidity and Mortality in Adult Spinal Deformity Surgery. Spine (Phila Pa 1976) 2017, 42(7):465-470.

14. Elsamadicy AA, Adogwa O, Sergesketter A, Vuong VD, Lydon E, Behrens S, Cheng J, Bagley CA, Karikari IO. Reduced Impact of Smoking Status on 30-Day Complication and Readmission Rates After Elective Spinal Fusion ( $\geq 3$ Levels) for Adult Spine Deformity: A Single Institutional Study of 839 Patients. World Neurosurg. 2017:107:233-8.

15. Hermann PC, Webler M, Bornemann R, Jansen TR, Rommelspacher $Y$, Sander K, Roessler PP, Frey SP, Pflugmacher R. Influence of smoking on spinal fusion after spondylodesis surgery: A comparative clinical study. Technol Health Care. 2016;24(5):737-44.

16. Seicean A, Seicean S, Alan N, Schiltz NK, Rosenbaum BP, Jones PK, Neuhauser D, Kattan MW, Weil RJ: Effect of smoking on the perioperative outcomes of patients who undergo elective spine surgery. Spine (Phila Pa 1976) 2013, 38(15):1294-1302.

17. Hilibrand AS, Fye MA, Emery SE, Palumbo MA, Bohlman HH. Impact of smoking on the outcome of anterior cervical arthrodesis with interbody or strut-grafting. J Bone joint Surg Am. 2001;83(5):668-73.

18. Tu TH, Kuo CH, Huang WC, Fay LY, Cheng H, Wu JC. Effects of smoking on cervical disc arthroplasty. J Neurosurg Spine. 2019;30(2):168-74.

19. McAfee PC, Cunningham BW, Devine J, Williams E, Yu-Yahiro J. Classification of heterotopic ossification $(\mathrm{HO})$ in artificial disk replacement. J Spinal Disord Tech. 2003;16(4):384-9.
20. He J, Liu H, Wu T, Ding C, Huang K, Hong Y, Wang B. Association between anterior bone loss and anterior heterotopic ossification in hybrid surgery. BMC Musculoskelet Disord. 2020;21(1):664.

21. Saleh KJ, Thongtrangan I, Schwarz EM. Osteolysis: medical and surgical approaches. Clin Orthopaedics Related Res. 2004:427:138-47.

22. Cornuz J, Feskanich D, Willett WC, Colditz GA. Smoking, smoking cessation, and risk of hip fracture in women. Am J Medicine. 1999;106(3):311-4

23. Forsén L, Bjørndal A, Bjartveit K, Edna TH, Holmen J, Jessen V, Westberg $G$. Interaction between current smoking, leanness, and physical inactivity in the prediction of hip fracture. J Bone Mineral Res. 1994;9(11):1671-8

24. Nguyen TV, Kelly PJ, Sambrook PN, Gilbert C, Pocock NA, Eisman JA. Lifestyle factors and bone density in the elderly: implications for osteoporosis prevention. J Bone Mineral Res. 1994;9(9):1339-46.

25. Szulc P, Garnero P, Claustrat B, Marchand F, Duboeuf F, Delmas PD. Increased bone resorption in moderate smokers with low body weight: the Minos study. The J Clin Endocrinol Metab. 2002;87(2):666-74.

26. Chang CJ, Jou IM, Wu TT, Su FC, Tai TW. Cigarette smoke inhalation impairs angiogenesis in early bone healing processes and delays fracture union. Bone Joint Res. 2020;9(3):99-107.

27. Ueng SW, Lin SS, Wang CR, Liu SJ, Tai CL, Shih CH. Bone healing of tibial lengthening is delayed by cigarette smoking: study of bone mineral density and torsional strength on rabbits. JTrauma. 1999;46(1):110-5.

28. El-Zawawy HB, Gill CS, Wright RW, Sandell LJ. Smoking delays chondrogenesis in a mouse model of closed tibial fracture healing. J Orthopaedic Res. 2006;24(12):2150-8.

29. Davies CS, Ismail A: Nicotine has deleterious effects on wound healing through increased vasoconstriction. BMJ (Clinical research ed) 2016, 353:i2709.

30. Gaston MS, Simpson AH. Inhibition of fracture healing. J Bone Joint Surg Brit . 2007;89(12):1553-60.

31. Michnovicz JJ, Hershcopf RJ, Naganuma H, Bradlow HL, Fishman J. Increased 2-hydroxylation of estradiol as a possible mechanism for the anti-estrogenic effect of cigarette smoking. New England J Med. 1986;315(21):1305-9.

32. Wang XF, Meng Y, Liu H, Hong Y, Wang BY. Anterior bone loss after cervical disc replacement: A systematic review. World J Clin Cases. 2020;8(21):5284-95.

33. Wu TK, Liu H, Wang BY, He JB, Ding C, Rong X, Yang Y, Huang KK, Hong $Y$. Incidence of bone loss after Prestige-LP cervical disc arthroplasty: a single-center retrospective study of 396 cases. Spine J. 2020;20(8):1219-28.

34. Hacker FM, Babcock RM, Hacker RJ: Very late complications of cervical arthroplasty: results of 2 controlled randomized prospective studies from a single investigator site. Spine (Phila Pa 1976) 2013, 38(26):2223-2226.

35. Xu J, Qiu X, Liang Z, Smiley-Jewell S, Lu F, Yu M, Pinkerton KE, Zhao D, Shi B. Exposure to tobacco smoke increases bone loss in spontaneously hypertensive rats. Inhalation Toxicol. 2018;30(6):229-38.

36. Moretto Nunes CM, Bernardo DV, Ferreira CL, Gomes MF, De Marco AC, Santamaria MP, Jardini MAN. Influence of Cigarette Smoke Inhalation on an Autogenous Onlay Bone Graft Area in Rats with Estrogen Deficiency: A Histomorphometric and Immunohistochemistry Study. Int J Mol Sci. 2019; 20(8):1854.

37. Nunley PD, Cavanaugh DA, Kerr EJ 3rd, Utter PA, Campbell PG, Frank KA, Marshall KE, Stone MB. Heterotopic Ossification After Cervical Total Disc Replacement at 7 Years-Prevalence, Progression, Clinical Implications, and Risk Factors. Int J Spine Surg. 2018;12(3):352-61.

38. Jin YJ, Park SB, Kim MJ, Kim KJ, Kim HJ. An analysis of heterotopic ossification in cervical disc arthroplasty: a novel morphologic classification of an ossified mass. Spine J. 2013;13(4):408-20.

39. Hui N, Phan K, Kerferd J, Lee M, Mobbs RJ. Prevalence of and Risk Factors for Heterotopic Ossification After Cervical Total Disc Replacement: A Systematic Review and Meta-Analysis. Global Spine J. 2020;10(6):790-804.

40. Wahood W, Yolcu YU, Kerezoudis P, Goyal A, Alvi MA, Freedman BA, Bydon M. Artificial Discs in Cervical Disc Replacement: A MetaAnalysis for Comparison of Long-Term Outcomes. World Neurosurg. 2020;134:598-613.e595. 
41. Zeng J, Liu H, Chen H, Rong X, Meng Y, Yang Y, Deng Y, Ding C: Effect of Prosthesis Width and Depth on Heterotopic Ossification After Cervical Disc Arthroplasty. Spine (Phila Pa 1976) 2019, 44(9):624-628.

42. Hu L, Zhang J, Liu H, Meng Y, Yang Y, Li G, Ding C, Wang B. Heterotopic ossification is related to change in disc space angle after Prestige-LP cervical disc arthroplasty. Eur Spine J. 2019;28(10):2359-70.

43. Suchomel P, Jurák L, Antinheimo J, Pohjola J, Stulik J, Meisel HJ, Čabraja M, Woiciechowsky C, Bruchmann B, Shackleford I, et al. Does sagittal position of the CTDR-related centre of rotation influence functional outcome? Prospective 2-year follow-up analysis. Eur Spine J. 2014;23(5):1124-34.

\section{Publisher's Note}

Springer Nature remains neutral with regard to jurisdictional claims in published maps and institutional affiliations.
Ready to submit your research? Choose BMC and benefit from:

- fast, convenient online submission

- thorough peer review by experienced researchers in your field

- rapid publication on acceptance

- support for research data, including large and complex data types

- gold Open Access which fosters wider collaboration and increased citations

- maximum visibility for your research: over $100 \mathrm{M}$ website views per year

At BMC, research is always in progress.

Learn more biomedcentral.com/submissions 